\title{
MAPEAMENTO DAS COMPETÊNCIAS COMPORTAMENTAIS UTILIZADAS PELOS PROFISSIONAIS CONTÁBEIS DO SESCON-SP
}

$\begin{array}{ll}\text { Recebido em } & 17.12 .2017 \\ \text { Aprovado em } & 22.12 .2017\end{array}$

\section{Valdério Matias da Silva}

Gerente de Contabilidade e Controles Internos no ASSAÍ Atacadista - GPA; experiência em auditoria externa na EY; professor de Contabilidade de cursos de curta duração na IOB - SAGE; bacharel em Ciências Contábeis pela Universidade Presbiteriana Mackenzie; MBA em Gestão Financeira, Controladoria e Auditoria pela FGV; mestre em Controladoria e Finanças Empresariais pela Universidade Presbiteriana Mackenzie; Personal \& Professional Coaching pela SBCoaching; membro da ANEFAC; e membro do Instituto dos Auditores Internos do Brasil. E-mail: valderio.matias@hotmail.com

\section{RESUMO}

Este trabalho tem por objetivo mapear as competências comportamentais utilizadas pelos profissionais contábeis no ambiente organizacional. Como base teórica para o estudo, foi utilizado o Diagnóstico M.A.R.E. de Orientações Motivacionais para o mapeamento das competências dos profissionais contábeis. O trabalho foi desenvolvido a partir da aplicação de questionário com perguntas estruturadas. Os questionários foram enviados a cerca de 450 profissionais contábeis do Sindicato das Empresas de Serviços Contábeis e das Empresas de Assessoramento, Perícias, Informações e Pesquisas do Estado de São Paulo (Sescon-SP). Ao final, obteve-se uma amostra de 66 respondentes com todas as respostas válidas, sendo todos empresários contábeis. Os dados foram analisados com estatística descritiva para a avaliação 
das correlações entre os constructos sugeridos pelo referencial teórico. Este trabalho tem implicações práticas aos profissionais contábeis do Sescon-SP, porque apresenta oportunidades de melhorias nos programas para o desenvolvimento das competências comportamentais. As questões exploradas neste trabalho ajudam na construção de novos cursos e treinamentos a serem desenvolvidos pelo Sescon-SP.

\section{PALAVRAS-CHAVE}

Profissional Contábil. Competências Comportamentais. IES3. Diagnóstico M.A.R.E. de Orientações Motivacionais. 


\section{INTRODUÇÃO}

Os profissionais contábeis vêm sofrendo modificações no seu papel dentro das organizações. Diante disso, diversas pesquisas são realizadas sobre as competências do profissional contábil.

Nessa linha, faz-se necessário mapear e entender as competências comportamentais mais adequadas para que os profissionais contábeis estejam preparados para assumirem com mais habilidades e conhecimentos esses novos desafios.

Para Coda (2016), as competências comportamentais são também entendidas como aquelas que possibilitam maior probabilidade de obtenção de sucesso na execução de determinadas atividades, podendo ser inerentes às características de personalidade de um indivíduo. Entretanto, antes de se aprofundar nas competências comportamentais dos profissionais contábeis, é necessário entender as diferentes visões sobre o conceito de competência.

O termo "competência" vem sendo estudado por diversos pesquisadores desde a década de 1970, e inicialmente pode-se resumir como, na visão das escolas americanas, o conjunto de qualificações que o profissional necessita ter para a rea- lização do trabalho, e, na visão europeia, a competência é colocar em prática o que se sabe em determinado ambiente. É válido reforçar o termo competência, para a escola americana, equivale ao termo competency e competence, para a europeia.

Quando se fala em competência no ramo da Contabilidade, há fatores que alteram o papel dos profissionais contábeis, dos quais se podem nomear a inovação tecnológica, as novas políticas tributárias, que convergem diretamente com a contabilidade, bem como o mercado de atuação, concorrentes, o conhecimento de outros idiomas e a gestão de pessoas.

$\mathrm{O}$ mercado e os órgãos reguladores da profissão contábil entendem que os profissionais contábeis necessitam se atualizar continuamente e se adaptar às novas exigências, tendo como objetivo o preparo para assumirem novas posições e visibilidade representativa dentro das empresas. Essa postura está em linha com a visão do Conselho Federal de Contabilidade (CFC), que, em 10 de dezembro de 2015, emitiu a Norma Brasileira de Contabilidade, a NBC PG 12 (R1) Educação Profissional Continuada.

Ainda na linha da definição de competências exigidas para o exercício da profissão contábil, em 2017, a International 
Accoutants Education Standard Board (Iaesb) emitiu a revisão final da International Education Standard 3 (IES3), norma estabelecida pela International Federation of Accountants (IFA), que elenca o conjunto de habilidades que os profissionais contábeis necessitam para sua adequada qualificação. A IES3 cita como necessárias quatro habilidades para que o profissional contábil exerça sua função com competência: i) intelectual; ii) pessoal; iii) interpessoal e de comunicação; e iv) organizacional.

Os órgãos nacionais e internacionais da classe contábil têm definido as competências que os profissionais contábeis devem ter para exercer a profissão de contador. Dessa forma, este estudo tem como objetivo: mapear as competências comportamentais dos profissionais afiliados ao Sindicato das Empresas de Serviços Contábeis e das Empresas de Assessoramento, Perícias, Informações e Pesquisas do Estado de São Paulo (Sescon-SP), usando o Diagnóstico M.A.R.E. (CODA, 2016), com foco na identificação dos comportamentos preferidos dos profissionais em uma situação de trabalho.

O presente estudo motiva-se pelas dificuldades encontradas para o mapeamento das competências comportamentais dos profissionais contábeis, visando o seu melhor desenvolvimento, uma vez que a maioria dos estudos sobre o tema, na literatura brasileira e internacional concentra-se na discussão sobre as competências técnicas.

O objetivo proposto para este trabalho também foi motivado pela investigação das competências comportamentais entendidas importantes pelos profissionais contábeis do Sescon-SP para a execução de suas atividades nas organizações em que atuam.

O Sescon-SP possui diversos programas de treinamentos que contribuem para o desenvolvimento das competências técnicas e comportamentais dos seus associados. Dessa forma, espera-se contribuir também para o desenvolvimento de novos cursos para o aperfeiçoamento desses profissionais.

\section{REFERENCIAL TEÓRICO}

\section{que é competência?}

De acordo com Parry (1996), organizações de todo o mundo se uniram na busca para o entendimento do termo competência, tornando-se esse estudo base para decisões sobre contratação, treinamento, promoções e outras questões de recursos humanos. 
Há uma grande dificuldade na literatura nacional e estrangeira para a definição da terminologia "competência". Tal dificuldade gera variedades de termos utilizados por aqueles que se interessam pelo tema, podendo a competência ser entendida como: habilidade, conhecimento intelectual/técnico superior, atitude e capacidade.

McClelland (1973), ao introduzir o conceito de competência, a definiu como característica inerente a uma pessoa que pode estar relacionada a um desempenho superior quando da realização de determinada tarefa ou em certas situações.

As competências profissionais são os conjuntos dos conhecimentos, das habilidades e das atitudes necessárias ao profissional para que ele possa exercer suas atividades. Para Zarifian (2008, p. 68), a competência é a tomada de iniciativa e o assumir responsabilidade do indivíduo diante de situações profissionais com as quais se depara.

\section{Competência na visão das escolas} americana e europeia

$\mathrm{Na}$ visão das escolas americanas, a competência é o conjunto de qualificações que o profissional deveria ter para fazer certo trabalho com nível superior de desempenho, destacando-se nessa visão McClelland (1973), Boyatzis (1982) e Spencer Jr. e Spencer (1993).

Uma das definições mais difundidas para competência é a apresentada por Scott B. Parry (1996, p. 50):

\begin{abstract}
Competência é um agrupamento de conhecimentos, habilidades e atitudes (CHA) relacionadas, que afeta a maior parte de uma tarefa (papel ou responsabilidade), correlacionada à performance, que pode ser medido a partir de parâmetros bem aceitos, e que pode ser melhorado através de treinamento e desenvolvimento.
\end{abstract}

No estudo de Parry (1996), que adota a visão americana, as competências são inputs, os quais consistem em conjuntos de conhecimentos, atitudes e habilidades que interferem na capacidade de realização do indivíduo.

Na Figura 1, demonstra-se o que Parry (1996) mencionou em seu estudo. Conforme a Figura 1, pode-se dizer que ainda hoje é possível perceber que não há um consenso quanto à melhor definição para a 


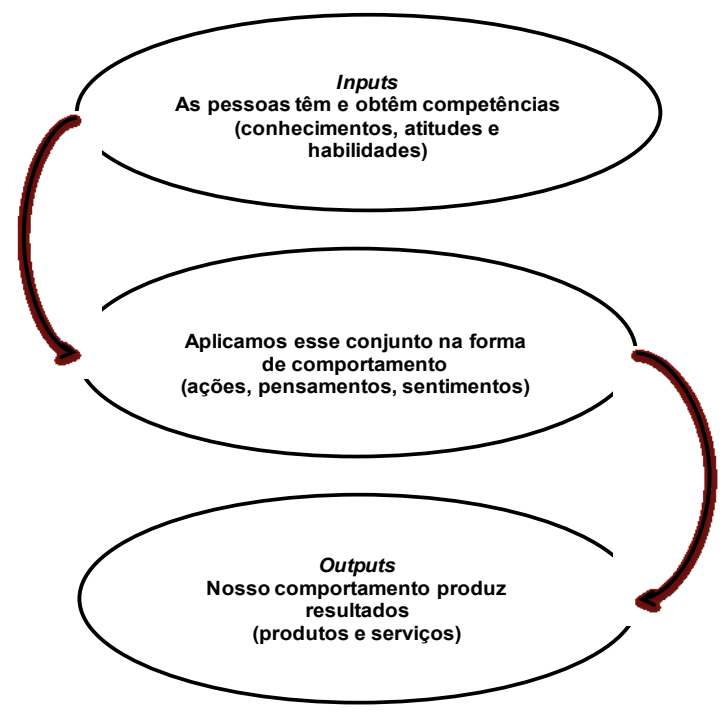

FIGURA 1 - Modelo do fluxo de competências Fonte: Parry (1996, p. 52). competência, o que possibilita dizer que não é uma questão concluída e possibilita por aqueles que estudam o tema.

$\mathrm{Na}$ contramão da visão das escolas americanas, Le Boterf (1994) diz que a competência não é estado que se tem, nem é resultado de treinamento. Competência é, na verdade, colocar em prática o que se sabe em determinado contexto, marcado geralmente pelas relações de trabalho, cultura da empresa, imprevistos, limitações de tempo e recursos. Pode-se, portanto, falar-se de competência apenas quando há competência em ação, isto é, ser competente é saber ser e mobilizar conhecimentos em diferentes contextos, é a capacidade de agir ou reagir.

Apresenta-se a seguir a Figura 2, inspirada em Le Boterf (1999):

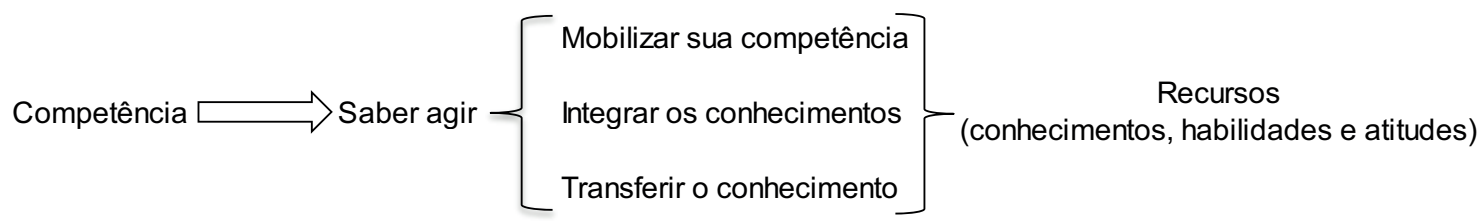

FIgURA 2 - Competência $=$ Saber agir

Fonte: Le Boterf (1999). 
Para Le Boterf (2003), a competência é uma disposição para agir de modo pertinente em relação a uma situação específica; o profissional contábil precisa estar preparado para enfrentar um mercado competitivo e apto a desenvolver novas competências e habilidades (SILVA, 2000).
A seguir, apresenta-se o Quadro 1 com um comparativo entre as duas linhas teóricas adaptadas com base no estudo de Sparrow e Bognanno (1993):

Conforme o Quadro 1, pode-se perceber que as duas abordagens contêm conceitos muitos diferentes, para tentar explicar o conceito do termo competência.

\begin{tabular}{|c|c|c|}
\hline & Competencies & Competences \\
\hline Definição & Linha Americana & Linha Europeia \\
\hline Descrição & $\begin{array}{l}\text { Conhecimentos, habilidades e atitudes com a } \\
\text { inclusão de alguns comportamentos pessoais. }\end{array}$ & $\begin{array}{l}\text { Repertórios comportamentais que as pessoas } \\
\text { trazem para um trabalho, papel ou contexto } \\
\text { organizacional. }\end{array}$ \\
\hline Identificado através & $\begin{array}{l}\text { Análise funcional dos trabalhos } \\
\text { desempenhados e responsabilidades. }\end{array}$ & $\begin{array}{l}\text { Técnicas de investigação baseadas em eventos } \\
\text { comportamentais. }\end{array}$ \\
\hline Focado em & $\begin{array}{l}\text { Técnicas de análise focadas na tarefa que } \\
\text { refletem expectativas no desempenho do } \\
\text { trabalho. }\end{array}$ & $\begin{array}{l}\text { Técnicas de análise centradas na pessoa, que } \\
\text { refletem a eficácia. }\end{array}$ \\
\hline Significado por & $\begin{array}{l}\text { Áreas ou campos de conhecimentos que uma } \\
\text { pessoa deve realizar efetivamente. }\end{array}$ & $\begin{array}{l}\text { O que pessoas precisam trazer para realizar a } \\
\text { função com determinado nível. }\end{array}$ \\
\hline $\begin{array}{l}\text { Critério de } \\
\text { desempenho }\end{array}$ & Enuncia um padrão. & $\begin{array}{l}\text { Características de uma performance individual } \\
\text { superior (excelência). }\end{array}$ \\
\hline Aplicação & $\begin{array}{l}\text { Padrões genéricos por meio das organizações e } \\
\text { das ocupações. }\end{array}$ & $\begin{array}{l}\text { Excelente comportamento sob medida para a } \\
\text { organização. }\end{array}$ \\
\hline Níveis de análise & $\begin{array}{l}\text { Ocupação ou setor baseado em uma amostra de } \\
\text { postos-chave. }\end{array}$ & Níveis de trabalho ou hierarquia gerencial. \\
\hline Domínio & $\begin{array}{l}\text { Competência dominada por instituições ou } \\
\text { organizações e concedidas para o indivíduo. }\end{array}$ & $\begin{array}{l}\text { Competência contida em um indivíduo e } \\
\text { trazida para a organização. }\end{array}$ \\
\hline Ônus da avaliação & Seleção a fim de conceder prestígio profissional. & $\begin{array}{l}\text { Identificação de potencial a fim de assegurar o } \\
\text { desenvolvimento profissional. }\end{array}$ \\
\hline Motivação individual & Realização que se pode transferir. & Realização que se pode estimular. \\
\hline
\end{tabular}

QUADRO 1 - Comparativo dos conceitos de competências Fonte: Sparrow e Bognanno (1993, p. 50-54). 
Para Coda (2016) o termo competência no contexto francês é visto em três dimensões: i) competências teóricas (conhecimentos); ii) saber-fazer (competências práticas ou funcionais); e iii) saber-ser (competências sociais e comportamentais). Ainda de acordo com Coda (2016), a diferença é que a escola americana considera como competente alguém que possua uma característica que se acredita a um desempenho de excelência, independentemente se esse indivíduo a utiliza ou não. Já a escola francesa considera competente alguém que demonstra aplicar essa característica, gerando um resultado desejado e observável.

No entendimento de Perrenoud (1999) e Rabaglio (2001), competência representa um conjunto de elementos estruturados entre si, a serem acionados na resolução de problemas. São eles: conhecimento, habilidade e atitude (CHA).

Para Fleury e Fleury (2001), entende-se por competência a capacidade de algo ou alguém realizar determinada ação com sucesso.

Gaspar (2004) complementa que as competências não são desenvolvidas através do ensinamento propriamente dito, mas sim pela criação de condições capazes de estimular o seu desenvolvimento.
De acordo com Camelo e Angerami (2013), a construção da competência profissional está vinculada tanto à aquisição de escolaridade quanto à de processos de aprendizagem informais que ocorrem em momentos e espaços distintos.

\section{Competência do profissional contábil}

Quando se fala em competências na profissão contábil, percebe-se que os estudos publicados se misturam com as funções e as atividades do profissional.

Após vasta revisão na literatura sobre a competência do contador, Cardoso (2006) afirma que na maioria dos casos pode-se perceber que:

- a maior parte dos estudos sobre a competência do contador trata da função do profissional, e não de competências;

- a quase totalidade dos estudos não realiza testes empíricos e sequer trata do aspecto da competência pelo enfoque da psicologia e dos recursos humanos; e - os estudos dos órgãos reguladores demonstram maior estruturação conceitual e a preocupação em evoluir a discussão que propõe. 
Ainda como fatores que alteram o papel dos profissionais contábeis, podem-se nomear a inovação tecnológica, as novas políticas tributárias que convergem diretamente com a contabilidade, bem como o mercado de atuação, os concorrentes, o conhecimento de outros idiomas e a gestão de pessoas. Todos esses fatores exigem que os profissionais da contabilidade adquiram novas habilidades para terem uma atuação proativa. Os profissionais contábeis precisam se manter atualizados e constantemente desenvolver suas competências técnicas agregadas aos novos conhecimentos, habilidades e atitudes que o mercado vem exigindo.

Para Colossi, Biazus e Rossi Madruga (2016), o trabalho dos profissionais contábeis não são apenas atividades técnicas, mas também o exercício de uma função social a ser realizada com e por meio de pessoas, cuja missão é contribuir para a realização dos objetivos da empresa e permitir a análise e a continuidade dos negócios.

Além disso, os profissionais contábeis necessitam expandir suas competências além dos números, desenvolvendo suas habilidades relacionadas à forma como tratam os problemas em seu dia a dia de trabalho. O mercado busca um profissional que se dedique a decisões e a previsões futuras, além do papel tradicional do contador, olhando para dados e informações obtidos no passado (MACHADO; FREITAS; OLIVEIRA, 2012).

Ainda nessa linha, para Reis, Sediyama, Moreira e Moreira (2015), o profissional contábil passou a ser visto como oportunidade de negócio, ou seja, um diferencial para a administração das empresas na medida em que deixa de cumprir apenas as obrigações acessórias e passa a participar mais ativamente do processo gerencial das empresas.

Para Espejo, Portulhak e Raffaelli (2016), presume-se que a reputação dos profissionais contábeis é um fator relevante para que os usuários da informação contábil sejam eles internos e externos à organização, atribuam confiabilidade às informações a eles destinadas, o que também pode influenciar o relacionamento entre a entidade e seu ambiente e na busca da eficiência dentro das organizações.

Na opinião de Pan e Seow (2016), os profissionais contábeis também necessitam lidar com demandas de tecnologia da informação que estão diretamente relacionadas a atividades contábeis.

Essas mudanças no papel do contador são expressas pelo Conselho Federal de 
Contabilidade (CFC, 2010), que declara que o mercado busca contratar profissionais contábeis com diversas habilidades gerenciais, demonstrando-se proativos e com a exigência de se manterem atualizados.

O mercado e os órgãos reguladores da profissão contábil entendem que os profissionais contábeis necessitam se atualizar continuamente e se adaptar às novas exigências, tendo como objetivo estar preparado para assumir novas posições e ter visibilidade representativa dentro das empresas. Essa postura está em linha com a visão do Conselho Federal de Contabilidade (CFC), que, em 10 de dezembro de 2015, emitiu a Norma Brasileira de Contabilidade, a NBC PG 12 (R1) - Educação Profissional Continuada, exigindo, a partir desse mesmo ano, para os auditores independentes, a obrigatoriedade de cumprimento de uma carga horária de treinamento. Da mesma forma, a partir de $1^{\circ}$ de janeiro de 2016, a exigência se aplica aos profissionais contábeis que exercem a função de gerência ou chefia no processo de elaboração das demonstrações contábeis das empresas sujeitas à contratação de auditores independentes ou consideradas empresas de grande porte nos termos da Lei n. $11.638 / 2007$.
Segundo Tamer, Viana, Soares e Lima (2013), são os conhecimentos mais exigidos pelo mercado, em ordem decrescente de solicitação: (i) Experiência profissional; (ii) Tecnologia da informação; (iii) Contabilidade geral e tributária; (iv) "Outros conhecimentos" (sendo o conjunto de: MBA, disponibilidade e espírito de liderança); (v) Contabilidade gerencial; (vi) Idiomas; (vii) Normas contábeis internacionais (IFRS); e (viii) Áreas não específicas da contabilidade.

Para Ahadiat e Martin (2016), o ensino de habilidades técnicas tradicionais pode não ser mais adequado para capacitar os estudantes de contabilidade, tendo em vista o número de vagas disponíveis, havendo a necessidade de uma maior capacitação desses estudantes.

Pode-se perceber que há no Brasil e no mundo uma preocupação na formação das competências comportamentais do contador, tendo em vista as mudanças exigidas pelo mercado sobre a participação dos profissionais contábeis na tomada de decisão.

\section{Conhecendo o diagnóstico M.A.R.E.} de orientações motivacionais

O Diagnóstico M.A.R.E. foi construído e validado por um processo que teve a duração 
de dois anos, com o uso de uma amostra de gerentes e profissionais ocupando cargo de nível superior de escolaridade em abrangência nacional (CODA, 2016). É um instrumento em forma de questionário, que tem por objetivo aferir situações de trabalho tendências ou preferências no modo de agir de cada profissional, ou seja, busca identificar as competências comportamentais que o profissional entende possuir ou não (CODA, 2016).

O Diagnóstico M.A.R.E. de Orientações Motivacionais não tem respostas certas ou erradas, mas possui a identificação daquilo que o profissional julga ser mais importante ou gosta mais de fazer (CODA, 2016).

São quatro as orientações motivacionais mapeadas através do Diagnóstico M.A.R.E.:

- Mediadora: foco em comportamentos voltados para a integração e a adaptação.

- Analítica: foco em comportamentos voltados para a definição de processos e estratégias.

- Receptiva: foco em comportamentos voltados para lidar com pessoas.

- Empreendedora: foco em comportamentos voltados para a consecução de resultados, objetivos e metas.

\section{PROCEDIMENTOS METODOLÓGICOS}

\section{Método de pesquisa}

Quanto ao seu objetivo, esta pesquisa foi exploratória, tendo em vista que busca respostas para o desconhecido, uma vez que buscou mapear as competências comportamentais utilizadas pelos profissionais contábeis do Sescon-SP que são essenciais na execução das suas atividades.

Para isso, foram mapeadas as competências comportamentais utilizadas pelos profissionais cadastrados no Sescon-SP através do Diagnóstico M.A.R.E. de Orientações Motivacionais.

Para Silva (2008), a pesquisa exploratória tem como objetivo proporcionar maior familiaridade com o problema, para torná-lo mais explícito ou para construir hipóteses. Na visão de Beuren et al. (2014), a pesquisa exploratória consiste no aprofundamento de conceitos preliminares sobre determinada temática não contemplada de modo satisfatório anteriormente. Assim, contribui para o esclarecimento de questões superficialmente abordadas sobre o assunto.

Quanto à abordagem do problema, a pesquisa foi quantitativa, que, segundo 
Richardson (1999, p. 70), se caracteriza pelo emprego de quantificação tanto nas modalidades de coleta de informações quanto no tratamento delas por meio de técnicas estatísticas, desde as mais simples, como percentual, média, desvio-padrão, às mais complexas, como coeficientes de correlação, análise de regressão etc. De acordo com Beuren et al. (2014), a abordagem quantitativa é frequentemente aplicada nos estudos descritivos, que procuram descobrir e classificar a relação entre variáveis e a relação de causalidade entre fenômenos.

Com relação ao procedimento, esta pesquisa caracteriza-se como uma pesquisa de levantamento ou survey, e os conteúdos foram coletados por meio do uso do Diagnóstico M.A.R.E. de Orientações Motivacionais, elaborado por Coda (2016).

\section{População e amostra}

A coleta dos dados foi possível graças ao contrato de colaboração técnica-científica entre a Universidade Presbiteriana Mackenzie e o Sescon-SP, que demonstrou interesse em participar desta pesquisa. Os dados foram coletados por meio de um questionário em formato eletrônico. Foi enviada uma carta convite às empresas participantes do
Programa de Qualidade de Empresas Contábeis (PQEC) do Sescon-SP, e foram apresentados o tema a ser discorrido e os objetivos propostos; nesse comunicado, foi também enviado um link direto, com uma senha personalizada para o preenchimento do Diagnóstico M.A.R.E. O comunicado foi encaminhado para 450 associados, e, desses, 66 responderam a pesquisa $(14,7 \%$ da base total).

A pesquisa foi preenchida diretamente no Diagnóstico M.A.R.E. ${ }^{1}$, utilizando uma senha que foi distribuída nas chamadas. Os dados da pesquisa foram tratados pelo Prof. Dr. Roberto Coda, proprietário dos direitos autorais da ferramenta, e nos foram encaminhados os resultados das orientações e dos perfis dos respondentes para que fossem analisados nesta pesquisa com as seguintes informações: i) gênero (mulher ou homem); ii) escolaridade; iii) formação; iv) idade; v) ano de formação; vi) tempo de experiência profissional; e vii) orientação e perfil dos respondentes de acordo com o Diagnóstico M.A.R.E. de Orientações Motivacionais.

$1<$ http://perfilmotivacional.com.br/questionario $>$ 


\section{Procedimento de coleta de dados}

Os dados foram coletados por meio do Diagnóstico M.A.R.E. de Orientações Motivacionais, que é um instrumento em forma de questionário com 16 perguntas, com quatro alternativas que a complementam.

Para cada questão, faz-se necessário dar uma nota de 1 a 4 , porém elas devem ser utilizadas uma única vez para cada alternativa, e os respondentes deveriam: dar nota 4 - para a alternativa que mais se aproxima da forma pela qual prefere agir; dar nota 3 - para a alternativa que for quase que inteiramente parecida com a forma pela qual prefere agir; dar nota 2 - para a alternativa que for muito pouco parecida com a forma pela qual prefere agir; e dar nota 1 - para alternativa que não for em nada parecida com a forma pela qual prefere agir.

\section{ANÁLISE DOS RESULTADOS}

O Diagnóstico M.A.R.E. é utilizado para a investigação acadêmica e de consultoria. Nessa linha, apresentam-se os resultados da pesquisa realizada junto aos associados do Sescon-SP. No Gráfico 1, apresenta-se o perfil dos respondentes.
Conforme o Gráfico 1, a amostra dos 66 respondentes foi representada por 29 mulheres (43,9\%) e 37 homens (56,1\%). Considerando o número total de respondentes, tem-se identificado o nível de escolaridade, e a maior parte dos respondentes tem ensino superior completo.

Ao analisar a experiência profissional dos respondentes, tem-se o Gráfico 2.

De acordo com o Gráfico 2, pode-se observar que os profissionais contábeis com experiência profissional com até cinco anos representam 3 respondentes (4,5\%); seguido por 12 respondentes (18,2\%) de 6 a 10 anos; 11 respondentes $(16,7 \%)$ de 11 a 15 anos; 6 respondentes $(9,1 \%)$ de 16 a 20 anos; e 34 respondentes $(51,5 \%)$ acima de 20 anos de experiência profissional. Verifica-se que a concentração da experiência profissional das mulheres está entre 6 e 10 anos e acima de 20 anos; quanto à concentração da experiência profissional dos homens, predomina o perfil entre 11 e 20 anos de experiência.

Na Tabela 1, apresenta-se a correlação dos perfis dos respondentes com a orientação motivacional do Diagnóstico M.A.R.E.

Conforme Tabela 1, as orientações motivacionais dominantes são a Mediadora e a Empreendedora, com 28,8\% de 


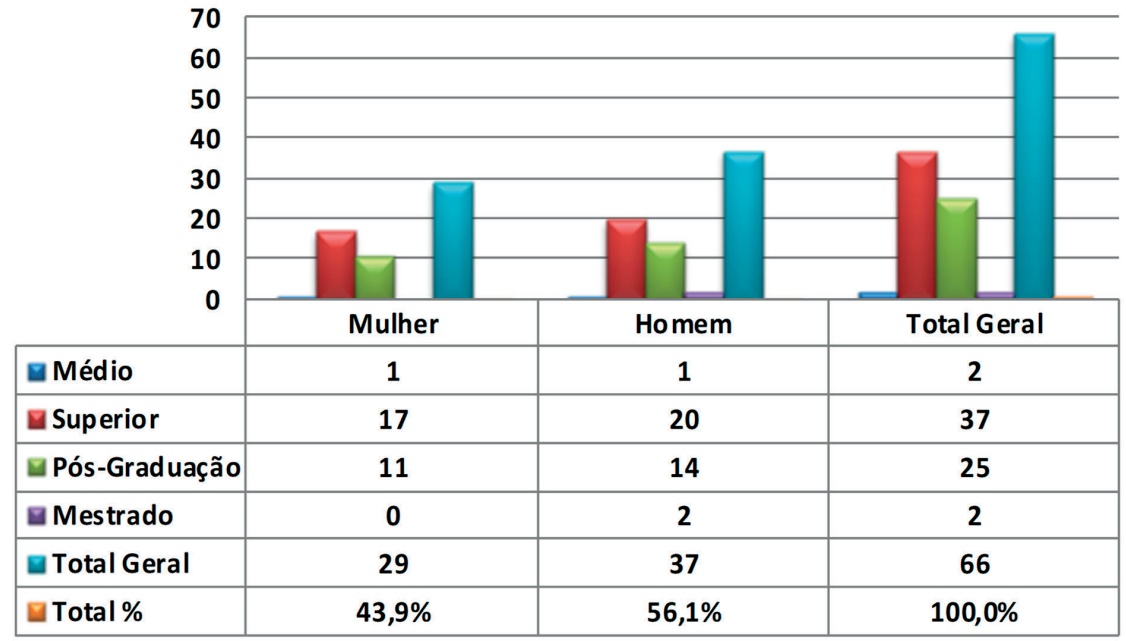

GRÁFICO 1 - Gráfico de nível de escolaridade Fonte: Elaborado pelo autor.

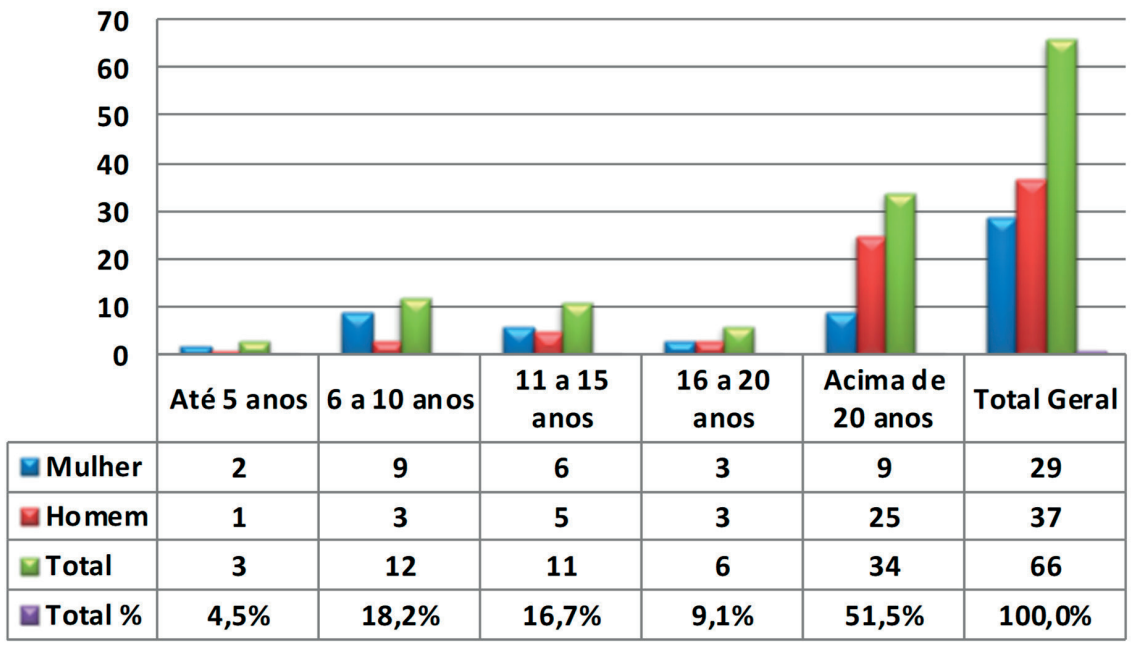

GRÁFICO 2 - Gráfico da experiência profissional Fonte: Elaborado pelo autor. 
TABELA 1 - Respondentes do Sescon-SP

\begin{tabular}{|c|c|c|c|}
\hline & & SESCON-SP & \\
\hline Perfil & Orientação & Quantidade & $\%$ \\
\hline Articulador & \multirow{3}{*}{$\begin{array}{c}\text { M. } \\
28,8 \%\end{array}$} & 9 & $13,6 \%$ \\
\hline Inovador & & - & $0,0 \%$ \\
\hline Motivador & & 10 & $15,2 \%$ \\
\hline Regulador & \multirow{3}{*}{$\begin{array}{c}\text { A. } \\
19,7 \%\end{array}$} & 3 & $4,5 \%$ \\
\hline Monitor & & 1 & $1,5 \%$ \\
\hline Coordenador & & 9 & $13,6 \%$ \\
\hline Facilitador & \multirow{3}{*}{$\begin{array}{c}\text { R. } \\
22,7 \%\end{array}$} & 1 & $1,5 \%$ \\
\hline Mentor & & 9 & $13,6 \%$ \\
\hline Considerador & & 5 & $7,6 \%$ \\
\hline Competidor & \multirow{3}{*}{$\begin{array}{c}\text { E. } \\
28,8 \%\end{array}$} & 2 & $3,0 \%$ \\
\hline Produtor & & 3 & $4,5 \%$ \\
\hline Realizador & & 14 & $21,2 \%$ \\
\hline Total & $100,0 \%$ & 66 & $100,0 \%$ \\
\hline
\end{tabular}

Fonte: Elaborada pelo autor. dominância, e na orientação Mediadora temos a ausência do perfil comportamental Inovador, e os perfis comportamentais Articulador e Motivador apresentam dominância de $13,6 \%$ e $15,2 \%$, respectivamente. Na orientação Empreendedora, o perfil comportamental Realizador se destaca com $21,2 \%$ do total de $28,8 \%$.

De acordo com a Tabela 1, os perfis comportamentais Articulador e Motivador possuem características em linha com o perfil dos respondentes do Sescon-SP, pois esses são profissionais que necessitam manter a harmonia no ambiente profissional para que haja a perenidade dos negócios; são responsáveis por garantir uma comunicação fácil, dar apoio a iniciativas voltadas à melhoria de processos, comunicam-se de forma produtiva, acreditam no que fazem e geram soluções de qualidade (CODA, 2016).

Ainda pode-se perceber que o perfil comportamental Realizador está em linha com os respondentes, tendo em vista que esses profissionais buscam fornecer respostas rápidas às questões ou às situações emergentes, age pautado pela objetividade e deixa claro o que precisa ser realizado (CODA, 2016).

Apresenta-se a Tabela 2 com a análise do perfil por gênero. Nela, observa-se que 
TABELA 2 - Perfil por gênero Sescon-SP

\begin{tabular}{|c|c|c|c|c|c|c|c|}
\hline \multicolumn{8}{|c|}{ Gênero } \\
\hline Perfil & Orientação & $\mathbf{F}$ & $M$ & Total Geral & $\mathrm{F} \%$ & $M \%$ & Total \% \\
\hline Articulador & \multirow{2}{*}{$\begin{array}{c}\text { M. } \\
28,8 \%\end{array}$} & 6 & 3 & 9 & $20,7 \%$ & $8,1 \%$ & $13,6 \%$ \\
\hline Motivador & & 3 & 7 & 10 & $10,3 \%$ & $18,9 \%$ & $15,2 \%$ \\
\hline Regulador & \multirow{3}{*}{$\begin{array}{c}\text { A. } \\
19,7 \%\end{array}$} & 3 & - & 3 & $10,3 \%$ & $0,0 \%$ & $4,5 \%$ \\
\hline Monitor & & 1 & - & 1 & $3,4 \%$ & $0,0 \%$ & $1,5 \%$ \\
\hline Coordenador & & 4 & 5 & 9 & $13,8 \%$ & $13,5 \%$ & $13,6 \%$ \\
\hline Facilitador & \multirow{3}{*}{$\begin{array}{c}\mathrm{R} . \\
22,7 \%\end{array}$} & - & 1 & 1 & $0,0 \%$ & $2,7 \%$ & $1,5 \%$ \\
\hline Mentor & & 1 & 8 & 9 & $3,4 \%$ & $21,6 \%$ & $13,6 \%$ \\
\hline Considerador & & 2 & 3 & 5 & $6,9 \%$ & $8,1 \%$ & $7,6 \%$ \\
\hline Competidor & \multirow{3}{*}{$\begin{array}{c}\text { E. } \\
28,8 \%\end{array}$} & - & 2 & 2 & $0,0 \%$ & $5,4 \%$ & $3,0 \%$ \\
\hline Produtor & & 1 & 2 & 3 & $3,4 \%$ & $5,4 \%$ & $4,5 \%$ \\
\hline Realizador & & 8 & 6 & 14 & $27,6 \%$ & $16,2 \%$ & $21,2 \%$ \\
\hline Total Geral & $100,0 \%$ & 29 & 37 & 66 & $100,0 \%$ & $100,0 \%$ & $100,0 \%$ \\
\hline Total \% & & $43,9 \%$ & $56,1 \%$ & $100,0 \%$ & & & \\
\hline
\end{tabular}

Fonte: Elaborada pelo autor.

há um equilíbrio entre mulheres e homens na orientação motivacional Mediadora (M.), e entre as mulheres há o perfil dominante com 9 respondentes (31,0\%), e entre os homens há o perfil dominante com 10 respondentes $(27,0 \%)$; a orientação motivacional Mediadora identifica pessoas que apresentam uma preocupação básica com a busca da compreensão e do equilíbrio entre pontos de vista aparentemente conflitantes na situação de trabalho (CODA, 2016).
Dentro da orientação motivacional Mediadora, o perfil comportamental Articulador possui maior dominância entre as mulheres com 6 respondentes (20,7\%), enquanto entre os homens foram 3 respondentes $(8,1 \%)$; já no perfil comportamental Motivador, entre as mulheres há baixa dominância com apenas 3 respondentes $(10,3 \%)$, e entre os homens há alta dominância com 7 respondentes (18,9\%).

Destaca-se, de forma negativa, na orientação motivacional Mediadora, o fato 
de não haver entre os respondentes o perfil comportamental Inovador, o qual está relacionado a profissionais que estão atentos à transformação do ambiente organizacional, toleram incertezas e riscos e com uma visão para novos projetos e desafios.

$\mathrm{Na}$ orientação motivacional Analítica (A.), as mulheres apresentam maior dominância com 8 respondentes $(27,5 \%)$, enquanto os homens apresentam 5 respondentes (13,5\%). A orientação motivacional Analítica caracteriza pessoas que apresentam uma preocupação básica com a busca da continuidade de ações e de processos, assim como o cumprimento de tarefas e de atividades dentro de elevados padrões e procedimentos de qualidade, são profissionais guiados pela lógica e pela racionalidade, possuindo no geral excelente visão de longo prazo (CODA, 2016).

Ao analisar os perfis comportamentais da orientação motivacional Analítica, destaca-se o perfil comportamental Coordenador, com perfil dominante aproximado entre as mulheres $(4-13,8 \%)$ e os homens (5 - 13,5\%), respectivamente; os profissionais com esse perfil compatibilizam esforços de diferentes áreas ou equipes, procuram garantir níveis adequados de confiança e respeito, definem o tempo necessário para a realização das tarefas (CODA, 2016).

Percebe-se na orientação motivacional Analítica que os homens não possuem os perfis comportamentais Regulador e Monitor, e, de acordo com Coda (2016), são profissionais com foco na continuidade dos negócios e qualidade das atividades realizadas, respectivamente. Pode-se verificar que, mesmo entre as mulheres, há uma baixa dominância no perfil comportamental Monitor.

$\mathrm{Na}$ orientação motivacional Receptiva (R.), as mulheres possuem baixa dominância, apresentando apenas 3 respondentes (10,3\%), enquanto os homens apresentam alta dominância com 12 respondentes $(32,4 \%)$; e a orientação motivacional Receptiva revela profissionais muito habilidosos para identificar os talentos das outras pessoas, demonstrando grande interesse tanto no desenvolvimento de suas habilidades e competências como das dos outros, fornecendo orientação e transferência de conhecimentos; são profissionais idealistas, otimistas e autoconfiantes (CODA, 2016).

Ainda na orientação motivacional Receptiva, destaca-se o perfil comportamental Mentor, em que os homens apresentam o perfil dominante com 8 respondentes $(21,6 \%)$, e profissionais com esse 
perfil dedicam-se ao desenvolvimento das pessoas por meio de uma orientação, encorajam o desenvolvimento das carreiras das pessoas, demonstram ser exigentes na seleção de empregados, desenvolvem a equipe para aceitar novos desafios, compartilham informações e ideias em todos os níveis hierárquicos (CODA, 2016).

No perfil comportamental Considerador, vê-se que há baixa dominância entre as mulheres e os homens $(2-6,9 \%)$ e $(3-8,1 \%)$, respectivamente, o qual se caracteriza por profissionais que encorajam as pessoas a encontrar o equilíbrio entre a vida pessoal e o trabalho, valorizam o trabalho em equipe $\mathrm{e}$ possuem facilidade para se relacionar.

No perfil comportamental Facilitador, verifica-se que não há respondentes entre as mulheres e que há baixa dominância entre os homens; profissionais com esse perfil fornecem feedback positivo, fornecem treinamento e planejam o desenvolvimento individual da equipe e executam ações voltadas para criar um ambiente de trabalho estimulante e produtivo.

Assim como na orientação motivacional Mediadora, percebe-se que há um equilíbrio entre as mulheres e os homens na orientação motivacional Empreendedora (E.), e as mulheres apresentam 9 res- pondentes (31\%) e os homens, 10 respondentes (27,0\%); na orientação motivacional Empreendedora, os profissionais são preocupados em realizar as coisas, fazendo que aquilo que foi planejado efetivamente aconteça, seguem seus instintos, buscando ou assumindo novas e mais complexas responsabilidades, atribuindo grande significado à consecução dos trabalhos e dos objetivos previstos (CODA, 2016).

Nos perfis comportamentais da orientação motivacional Empreendedora, vê-se que o perfil comportamental Realizador apresenta maior dominância entre as mulheres ( $8-27,6 \%)$ e os homens ( $6-16,2 \%)$, respectivamente, quando comparado com os demais perfis comportamentais. Os profissionais com o perfil comportamental Realizador defendem suas ideias com convicção, mas são flexíveis para mudar de opinião, são objetivos e são claros naquilo que precisa ser realizado.

No perfil comportamental Competidor, vê-se que não há respondentes entre as mulheres e baixa dominância entre os homens (2 - 5,4\%); profissionais com esse perfil desenvolvem esforços para conquistar mercado, gostam de desafios que dependam de atuação competitiva, são hábeis para escolher a equipe e chamam para 
si a responsabilidade para decidir o que deve ser feito.

O perfil comportamental Produtor também apresenta baixa dominância entre as mulheres $(1-3,4 \%)$ e os homens $(2-5,4 \%)$, respectivamente; os profissionais com esse perfil detêm elevado conhecimento para a realização do trabalho, apreciam desafios para poder demonstrar sua capacidade de atingir metas, definem claramente as estratégias antes de entrar em ação e exibem alto grau de interesse e de motivação.
Na Tabela 3, apresenta-se a orientação e o perfil do Diagnóstico M.A.R.E. pelo tempo de experiência profissional dos respondentes.

De acordo com a Tabela 3, pode-se verificar que do total dos 66 respondentes, 34 (51,5\%) possuem experiência profissional acima de 20 anos, enquanto apenas $3(4,5 \%)$ possuem experiência profissional com até 5 anos, fornecendo uma maior confiabilidade aos resultados apresentados na pesquisa por haver um

TABELA 3 - Orientação e perfil por tempo de experiência profissional

\begin{tabular}{|c|c|c|c|c|c|c|c|c|}
\hline \multirow[b]{2}{*}{ Perfil } & \multirow[b]{2}{*}{ Orientação } & \multicolumn{7}{|c|}{ Experiência profissional } \\
\hline & & $\begin{array}{l}\text { Até } 5 \\
\text { anos }\end{array}$ & $\begin{array}{l}6 \text { a } 10 \\
\text { anos }\end{array}$ & $\begin{array}{c}11 \text { a } 15 \\
\text { anos }\end{array}$ & $\begin{array}{c}16 \text { a } 20 \\
\text { anos }\end{array}$ & $\begin{array}{c}\text { Acima de } \\
20 \text { anos }\end{array}$ & $\begin{array}{l}\text { Total } \\
\text { Geral }\end{array}$ & $\%$ \\
\hline Articulador & \multirow{2}{*}{$\begin{array}{c}\text { M. } \\
28,8 \%\end{array}$} & - & 1 & 1 & 2 & 5 & 9 & $13,6 \%$ \\
\hline Motivador & & - & 5 & 2 & - & 3 & 10 & $15,2 \%$ \\
\hline Regulador & \multirow{3}{*}{$\begin{array}{c}\text { A. } \\
19,7 \%\end{array}$} & 1 & - & 1 & - & 1 & 3 & $4,5 \%$ \\
\hline Monitor & & - & 1 & - & - & - & 1 & $1,5 \%$ \\
\hline Coordenador & & 1 & 1 & - & - & 7 & 9 & $13,6 \%$ \\
\hline Facilitador & \multirow{3}{*}{$\begin{array}{c}\mathrm{R} . \\
22,7 \%\end{array}$} & - & - & - & - & 1 & 1 & $1,5 \%$ \\
\hline Mentor & & - & - & - & 1 & 8 & 9 & $13,6 \%$ \\
\hline Considerador & & - & - & 1 & 1 & 3 & 5 & $7,6 \%$ \\
\hline Competidor & \multirow{3}{*}{$\begin{array}{c}\text { E. } \\
28,8 \%\end{array}$} & - & 1 & - & - & 1 & 2 & $3,0 \%$ \\
\hline Produtor & & - & - & 1 & - & 2 & 3 & $4,5 \%$ \\
\hline Realizador & & 1 & 3 & 5 & 2 & 3 & 14 & $21,2 \%$ \\
\hline Total Geral & \multirow[t]{2}{*}{$100,0 \%$} & 3 & 12 & 11 & 6 & 34 & 66 & $100,0 \%$ \\
\hline Total $\%$ & & $4,5 \%$ & $18,2 \%$ & $16,7 \%$ & $9,1 \%$ & $51,5 \%$ & $100,0 \%$ & \\
\hline
\end{tabular}

Fonte: Elaborada pelo autor. 
alto nível de experiência profissional dos respondentes.

\section{CONSIDERAÇOES FINAIS}

O primeiro ponto a destacar refere-se ao perfil dos respondentes, no qual se pode perceber um equilíbrio de gêneros atuando na profissão contábil, nesta pesquisa representada por $43,9 \%$ de mulheres e $56,1 \%$ de homens.

O segundo ponto refere-se ao nível de escolaridade dos respondentes, com concentração no nível superior com 37 respondentes, seguido da pós-graduação com 25 respondentes e empatados o nível médio e mestrado com 2 respondentes. Cabe destacar que as mulheres e os homens com nível superior foram de 17 e 20 respondentes, respectivamente, e no nível do mestrado tivemos apenas homens respondentes.

Destaca-se no terceiro ponto a orientação motivacional dos respondentes do Sescon-SP, e os respondentes ficaram concentrados na orientação motivacional Mediadora e Empreendedora (28,8\%), o que valida a confiabilidade do Diagnóstico M.A.R.E., tendo em vista que os respondentes são proprietários de escritórios de contabilidade.
No quarto ponto, destaca-se que os profissionais contábeis do Sescon-SP apresentam perfis comportamentais de alta dominância, sendo os perfis comportamentais Motivador com 15,2\%, Coordenador e Mentor com 13,6\% e Realizador com 21,2\%.

No quinto ponto, destacam-se os perfis comportamentais de baixa significância entre os profissionais contábeis do Sescon-SP, sendo os perfis comportamentais Articulador com 13,6\%, Inovador sem respondentes, Regulador e Produtor com 4,5\%, Monitor e Facilitador com 1,5\%, Considerador com 7,6\% e Competidor com 3,0\%, o que demonstra haver uma necessidade na criação de cursos para os profissionais contábeis do Sescon-SP com o objetivo de desenvolver esses perfis comportamentais. $\mathrm{O}$ perfil inovador tem foco no mercado, pensamento criativo e visão de mudança.

Por fim, conclui-se haver um caminho a ser percorrido para o desenvolvimento dos profissionais contábeis no âmbito das competências comportamentais. De acordo com os resultados obtidos junto aos profissionais contábeis do Sescon-SP, constatou-se que competências comportamentais focadas na comunicação clara e concisa, escuta ativa, negociação, relacionamento interpessoal, pensamento inovador, dele- 
gação de atividades, liderança, qualidade nas entregas, ceticismo profissional e visão estratégica de longo prazo ainda são competências comportamentais que necessitam ser desenvolvidas, e que essas competências comportamentais devem ser integradas aos novos profissionais contábeis para que estejam preparados para assumirem maiores responsabilidades dentro das empresas em que atuam e assim fazer parte do time que tomam as decisões estratégicas para a continuidade das organizações, tendo uma visão de longo prazo e preparando seus empregados para que deem continuidade ao negócio.
Percebe-se ainda que os respondentes do Sescon-SP, com base nos resultados apresentados neste estudo, apresentam características de tocadores do negócio, formando e motivando seus colaboradores para a execução do trabalho. Dessa forma, os profissionais contábeis do Sescon-SP devem buscar o desenvolvimento das competências comportamentais de baixa dominância.

De acordo com os resultados apresentados nesta pesquisa, apresenta-se no Quadro 2 uma proposta de cursos para o desenvolvimento das competências comportamentais de baixa dominância dos

\begin{tabular}{|c|c|c|}
\hline Curso & IES3 & Perfil \\
\hline Negociação no ambiente de trabalho & \multirow{3}{*}{$\begin{array}{l}\text { Interpessoal e } \\
\text { comunicação }\end{array}$} & \multirow{3}{*}{ Articulador } \\
\hline Técnicas de escuta ativa & & \\
\hline Comunicação empresarial & & \\
\hline Empreendedorismo profissional & \multirow{3}{*}{ Intelectual } & \multirow{2}{*}{ Inovador } \\
\hline Habilidades para solução de problemas & & \\
\hline Qualidade dos entregáveis & & Regulador \\
\hline Delegação produtiva das atividades & \multirow{2}{*}{ Organizacional } & \multirow{2}{*}{ Competidor } \\
\hline Liderança & & \\
\hline Aplicação do ceticismo profissional & \multirow{3}{*}{ Pessoal } & Regulador \\
\hline Desenvolvimento das qualidades pessoais (Coaching) & & Considerador \\
\hline Visão estratégica de longo prazo & & Competidor \\
\hline
\end{tabular}

QUADRO 2 - Propostas de desenvolvimento profissional Fonte: Elaborada pelo autor. 
profissionais contábeis do Sescon-SP e que foram mapeadas pelo Diagnóstico M.A.R.E. de Orientação Motivacional. Cabe destacar que não se deve limitar aos cursos propostos, podendo ser desenvolvidos outros cursos para o desenvolvimento dos profissionais contábeis do Sescon-SP.

\section{MAPPING THE BEHAVIORAL SKILLS USED BY ACCOUNTING PROFESSIONALS OF SESCON-SP}

\section{ABSTRACT}

This work aims to at mapping behavioral competencies through accounting professionals in the organizational environment. As a theoretical basis for the study, there was the M.A.R.E. Diagnostic Orientations for mapping the skills of accounting professionals. The work was developed from the application of a questionnaire with structured questions. The questionnaires were sent to approximately 450 accounting professionals of the Sindicato das Empresas de Serviços Contábeis e das Empresas de Assessoramento, Perícias, Informações e Pesquisas do Estado de São Paulo (Sescon-SP). At the end of the research, a sample of 66 respondents with valid answers was obtained, all of them accounting entrepreneurs. The data were analyzed with descriptive statistics to evaluate the correlations between the constructs suggested by the theoretical reference. This work has practical implications for the accounting professionals of Sescon-SP since it presents opportunities for improvement in the programs for the development of behavioral competences. The questions explored this work help in the construction of new courses and training courses to be developed by Sescon-SP.

\section{KEYWORD}

Accounting Professional. Behavioral Skill. IES3. M.A.R.E. Diagnostic Orientations.

\section{REFERÊNCIAS}

AHADIAT, N; MARTIN, R. M. Necessary attributes, preparations, and skills for the selection and promotion of accounting professionals. Journal of Accounting and Finance, v. 16, n. 1, p. 11-25, 2016.

BEUREN, I. M.; LONGARAY, A. A.; RAUPP, F. M.; SOUSA, M. A. B. de; COLAUTO, R. D.; PORTON, R. A. de B. Como elaborar trabalhos monográficos em contabilidade: teoria e prática. 3. ed. São Paulo: Atlas, 2014.

BOYATZIS, R. E. The competente manager: a model for effective performance. New York: John Wiley \& Sons, 1982. 
CAMELO, S. H. H.; ANGERAMI, E. L. S. Competência profissional: a construção de conceitos, estratégias desenvolvidas pelos serviços de saúde e implicações para a enfermagem. Revista: Texto \& Contexto Enfermagem, v.22, n. 2, p. 522-560, 2013.

CARDOSO, R. L. Competências do contador: um estudo empírico. São Paulo, 2006, 169 f. Tese (Doutorado em Ciências Contábeis) - Universidade de São Paulo. São Paulo, 2006.

CODA, R. Competências comportamentais: como mapear e desenvolver competências pessoais no trabalho. São Paulo: Atlas, 2016.

COLOSSI, N.; BIAZUS, C. A.; ROSSI MADRUGA, S. Funções e competências gerenciais do contador. Revista de Administração da Universidade Federal de Santa Maria, n. 9, abril-junho, 2016.

CONSELHO FEDERAL DE CONTABILIDADE - CFC. Perfil do contabilista brasileiro 2009. Brasília, DF: CFC, 2010.

ESPEJO, M. M. dos S. B.; PORTULHAK, H.; RAFFAELLI, S. C. D. A imagem do profissional contábil: análise da percepção socialmente construída por estudantes de ciências econômicas. Revista Contemporânea de Contabilidade, v. 13, n. 29, p. 157-178, maio/ago. 2016.
FLEURY, A.; FLEURY, M. T. L. Construindo o conceito de competências. Revista de Administração Contemporânea, Rio de Janeiro, v. 5, ed. esp., p. 183-196, 2001.

GASPAR, M. I. Competências em questão: Contributo para a formação de professores. Portugal, 2004. Disponível em: <http://reposito rioaberto.uab.pt/bitstream/10400.2/158/1/ Discursos\%E2\%80\%93Forma\%C3\%A7\% C3\%A3o\%20de\%20Professores55-71.pdf>. Acesso em: 13 nov. 2016.

LE BOTERF, G. Compétence et navigation professionelle. Paris: Editions d'Organisation, 1999.

LE BOTERF, G. Desenvolvendo a competência dos profissionais. Porto Alegre: Artmed, 2003.

LE BOTERF, G. De La compétence: Essai sur um attracteur étrange. Paris: Editions d'Organizations, 1994.

MACHADO, D. G.; FREITAS, L. L. de; OLIVEIRA, A. F. de. Exigências do Mercado de Trabalho para o profissional contábil: um estudo realizado no Rio Grande do Sul. Revista do Conselho Regional de Contabilidade do Rio Grande do Sul, v. 148, p. $40-56,2012$.

McClELLAND, D. C. Testing for competence rather than for intelligence. American Psychologist, v. 28, n. 1, p. 1-14, 1973. 
NBC PG12 (R1) - EDUCAÇÃO CONTINUADA, 2015. Disponível em <http:// www.crcsp.org.br/portal/desenvolvimento/educacao-profissional-continuada/NBCPG12R1.pdf>. Acesso em: 25 set. 2016.

PAN, G.; SEOW, P.-S. Preparing accounting graduates for digital revolution: A critical review of information technology competences and skills development. Journal of Education for Business, v. 91, n. 3, p. 166-175, 2016.

PARRY, S. B. The Quest for Competencies. Training, v. 33, n. 7, p. 48-56, 1996.

PERRENOUD, P. Construir as competências desde a escola. Porto Alegre: Artmed, 1999.

RABAGLIO, M. O. Seleção por competências. 4. ed. São Paulo: Educator, 2001.

REIS, A. de O.; SEDIYAMA, G. A. S.; MOREIRA, V. de S.; MOREIRA, C. C. Perfil do Profissional Contábil: habilidades, competências e imagem simbólica. $R e$ vista Contemporânea de Contabilidade, v. 12, n. 25, p. 95-116, jan./abr. 2015.

RICHARDSON, R. J. Pesquisa social: métodos e técnicas. 3. ed. São Paulo: Atlas, 1999.

SILVA, A. C. R. da. Metodologia da pesquisa aplicada à contabilidade: orientações de estudos, projetos, artigos, relatórios, monografias, dissertações, teses. 2. ed. São Paulo: Atlas, 2008.
SILVA, T. M. Currículo flexível: evolução e competência. Revista Brasileira de Contabilidade, v. 29 , n. 121 , p. $22-27$, jan./ fev. 2000.

SPARROW, P. R.; BOGNANNO, M. Competency requirement forecasting: issues for international selection and assessment. International Journal of Selection and Assessment, v. 1, n. 1, p. 50-54, 1993.

SPENCER JUNIOR, L. M.; SPENCER, S. M. Competence at work: models for superior performance. New York: John Wiley, 1993. TAMER, C.; VIANA, C.; SOARES, L. A.; LIMA, M. Perfil do profissional contábil demandado pelo mercado de trabalho: um estudo no norte do Brasil. Revista Universo Contábil, Blumenau, v. 9, n. 3, p. 143-162, jul./set. 2013.

ZARIFIAN, P. Objetivo competência: por uma lógica. São Paulo: Atlas, 2008. 